\title{
Thalidomide embryopathy
}

INSERM

\section{Source}

INSERM. (1999). Orphanet: an online rare disease and orphan drug data base.

Thalidomide embryopathy. ORPHA:3312

Thalidomide embryopathy is a group of anomalies presented in infants as a result of in utero exposure (between 20-36 days after fertilization) to thalidomide, a sedative used in treatment of a range of conditions, including morning sickness, leprosy and multiple myeloma (see these terms). Thalidomine embryopathy is characterized by phocomelia, amelia, forelimb and hand plate anomalies (absence of humerus and/or forearm, femur and/or lower leg, thumb anomalies). Other anomalies include facial hemangiomas, and damages to ears (anotia, microtia), eyes (microphthalmia, anophthalmos, coloboma, strabismus), internal organs (kidney, heart, and gastrointestinal tract), genitalia, and heart. Infant mortality associated with thalidomide embryopathy is estimated to be as high as $40 \%$. Thalidomide is contraindicated in pregnancy and pregnancy prevention is recommended in women under treatment. 